\title{
Stressors Among Undergraduate Students at China Agricultural University: Practical Observations from Teaching Experience
}

\author{
David M Henneberry*1, Carolina Lopez Burrola ${ }^{2}$ and Heydi Calderon Ambelis ${ }^{1}$ \\ ${ }^{1}$ Department of Agricultural Economics, Oklahoma State University, USA \\ ${ }^{2}$ Department of Global Studies and Partnerships, Oklahoma State University, USA \\ *Corresponding author: David M. Henneberry, Department of Agricultural Economics, Oklahoma State University, USA \\ Carolina Lopez Burrola, Department of Global Studies and Partnerships, Oklahoma State University, USA \\ Heydi Calderon Ambelis, Department of Agricultural Economics, Oklahoma State University, USA
}

To Cite This Article: David M Henneberry, Carolina Lopez Burrola and Heydi Calderon Ambelis, Stressors Among Undergraduate Students at China Agricultural University: Practical Observations from Teaching Experience. Am J Biomed Sci \& Res. 2019 - 6(5). AJBSR.MS.ID.001064.

DOI: $10.34297 /$ AJBSR.2019.06.001064.

Received: 眥 December 05, 2019; Published: 泚 December 12, 2019

\section{Introduction}

Stress among college students is a factor that many institutions are not well equipped to handle. Yet, the many stressors this group faces pose a stark reality: Coping with high levels of stress at a time that they don't have the life experience or family support to deal with it. Students entering college are leaving their nuclear family, often getting a roommate, frequently starting a romantic relationship, getting a part time job and dealing with an employer, taking entrance exams, facing exams and quizzes in their classes, piling up a small mountain of student debt and trying to determine their future in a job market that offers diminishing possibilities. This altogether accounts for several years of a high stress environment that can leave them shaken and uncertain. This article contains some observations on stress faced by students at China Agricultural University (CAU) in Beijing. CAU is a highly ranked agricultural university in China with a focus on agriculture, biology, engineering, veterinary medicine, economics, management, humanities and social science [1]. The students are in a very competitive environment which challenges the faculty and administration to control, so that their educational experience can be both positive and productive. Albrecht's four types of stress provide a useful categorization tool for organizing our observations: Time, Anticipatory, Situational and Encounter Stress. We will provide some examples of each, which may help administrators to craft an institutional response.

\section{Time Stress: A College Student's Nightmare}

Everything in a college student's life happens on a timeline. From the start of the semester until finals week, they are in multiple classes, which have exams, quizzes, term papers and presentations happening on a temporal basis. They may or may not have the organizational skills to handle so many separate deadlines, but their constant evaluations (a grade in every course) mean that their future somewhat depends upon their ability to schedule and remember everything they need to accomplish. Students at China Agricultural University have a heavy load of not only classes, but extra-curricular activities. They are included as performers in university celebrations, such as the 25th anniversary of a college, as well as in national celebrations such as the 70th anniversary of the country's current government. These obligations on student time contribute to the stressful environment faced by these young academicians. There are two techniques which may help them with time management: the Pomodoro Technique and the Eisenhower Matrix [2].

The Pomodoro Technique is a way of accomplishing objectives within the time you have, rather than the time you wish you had. It was developed in the 1980's by Francesco Cirillo, who used a kitchen timer shaped like a tomato (hence the name Pomodoro, which is the Italian word for tomato) to break his time into intervals. For example, a student might write a short paper by spending 2 hours reading background material, one hour summarizing the conclusions of the readings, and another hour editing and formatting the paper. Thus, the paper, for better or for worse, would be accomplished in four hours. This leaves time for other assignments and deadlines, all of which also have points counting toward the final grade. The alternative to the Pomodoro technique is often procrastination, which can result in a disaster. The Eisenhower Matrix is a way of prioritizing activities based upon their importance and urgency. If something is both important and urgent it should be done first. If it is urgent but not important, delegate another person to do it. If it is important but not urgent it can be done later. Tasks that are neither important nor urgent should be deleted. 


\section{Anticipatory Stress: Something's Always on the Horizon}

Undergraduate student life and being constantly evaluated for your performance go hand in hand. A typical undergraduate student is enrolled in five courses, with each having an average of three examinations, four homework assignments and one term paper or class presentation. That equates to 40 evaluation events in a typical 12-week semester, an average of more than three per week. Most freshmen and sophomore students don't have fully developed time management skills, but they are aware of the upcoming deadlines. They anticipate, with stress, the events on which they will be evaluated by their professors and/or peers. Fatigue and lack of sleep can contribute to the anticipatory stress of getting assignments done on time. Performance anxiety is an underlying cause of anticipatory stress. Students can't meet their own, or their parent's, high expectations for performance in a competitive academic environment. A couple of methods for coping with anticipatory stress is meditation and self talk. Even though these techniques may be difficult to practice when living with six other rommates, meditation and self talk can teach an individual how to live in the here and now, and not letting their mental images of an imaginary future cause anxiety and stress. Both techniques have the additional advantage of not costing money - many tutorials are available online and students can practice them in their room.

\section{Situational Stress: New Experiences are a Daily Occurrence}

Situational stress is caused by a situation that the students find themselves in, often without warning and without having any control over the situation. For example, a student might be making a class presentation and be laughed at by his or her peers in the classroom. This type of event is very stressful for the age group of college students because peer pressure is so powerful at that age. Some forms of competition are unhealthy and create situational stress. Students might steal reading materials from the library so their competitors for grades don't have the opportunity to see the material (this hasn't been a problem at CAU but has happened at many educational institutions). Trying to study without access to the appropriate resources is a situational stress. Students tend to get sick when stressed out. Cortisol, a glucocorticoid (steroid hormone), is produced from cholesterol in the two adrenal glands located on top of each kidney. Cortisol is normally released in response to things like waking up in the morning, exercising, and acute stress. Too much cortisol weakens their immune system and decreases their ability to fight infection. Stress also makes students more susceptible to diseases that the immune system holds at bay, like cancer, but their young age is forgiving.

Language stress is also a part of the situational stress at China Agricultural University, where almost all the classes are offered in English and almost all the students are native speakers of Chinese. Performing academic tasks in a foreign language creates stress for students. One way of coping with situational stress is the 50/10 rule. Schedule every hour with 50 minutes for the activity and then 10 minutes to stretch, go to the bathroom, get a drink of water and "keep it together". Situational stress is exacerbated by being rushed and in a panic. Having a little maintenance time in the schedule can greatly increase an individual's ability to cope with situational stress.

\section{Encounter Stress: What are they Going to Do?}

Social encounters also contribute to college stress. Students often have conflict with peers, and they don't have the support of their nuclear family and childhood home at the end of the day. The conflicts could be the result of social interaction within friendships, attempts at romance, relationships with professors, extracurricular activities or competitions or any other of the many situations students find themselves in. A student at a university campus is surrounded by completely new relationships during the first two years of their program. Most have left behind the sheltering support of family and home-town friends. Every time they meet with someone they are establishing and developing a relationship, rather than basking in the comfort of an old friend. Thus, encounter stress is a common occurrence in their lives.

Encounter stress might be caused by an intimidating professor, a romance in trouble, a group project in an assignment, or interactions with authority such as campus life counselors or campus police. Any type of encounter with an individual the student would rather not see can be a source of encounter stress. Encounter stress can be dealt with by being proactive, controlling your reaction, keeping emotions in check and knowing your needs and goals. These are proven techniques for handling stressful situations involving difficult or high stress individuals.

\section{Conclusion}

Student stress is an important variable in academic success. This article utilized Albrecht's categorization of stress into four major areas: Time, Anticipatory, Situational and Encounter Stress. Time stress can be addressed by utilizing the Pomodoro technique and the Eisenhower Matrix. Anticipatory stress can be addressed by practicing meditation [3]. Situational stress can be reduced by implementing the 50/10 rule. Encounter stress can be dealt with by being proactive, controlling your reaction, keeping emotions in check and knowing your needs and goals. All four of Albrecht's categories of stress have suggested coping mechanisms which students can use to control the impact of stress upon their daily lives.

\section{References}

1. Cirillo Francesco (2019) The Pomodoro Technique-Proudly Developed by Francesco Cirillo.

2. (2019) Eisenhower-matrix.

3. Graham Robert J (2019) Albrechts-four-types-of-stress-managingcommon-pressures. 